\title{
Avaliação da composição regional e tecidual da carcaça ovina
}

\section{Luis Gustavo Castro Alves ${ }^{*}$, José Carlos da Silveira Osório², Maria Teresa Moreira Osório², Alexandre Rodrigo Mendes Fernandes ${ }^{3}$, Edson Luis de Azambuja Ribeiro ${ }^{4}$, Camila Magalhães da Cunha ${ }^{5}$, Hélio Ricardo de Almeida ${ }^{6}$, Ingrid Harumi de Souza Fuzikawa ${ }^{7}$}

\author{
${ }^{1}$ Méd. Vet., M. Sc. Doutorando em Ciência Animal, Universidade Estadual de Londrina, Londrina, Paraná; \\ ${ }^{2}$ Méd. Vet., D. Sc., Professor Visitante Nacional Sênior da CAPES/Universidade Federal da Grande Dourados- \\ UFGD, Dourados - Mato Grosso do Sul, Bolsista Produtividade CNPq; \\ ${ }^{3}$ Zootecnista, D. Sc., Professor do Curso e do Programa de Pós-Graduação em Zootecnia-UFGD; \\ ${ }^{4}$ Zootecnista, D. Sc., Professor do Programa de Pós-Graduação em Ciência Animal, Londrina, Paraná; \\ ${ }^{5}$ Zootecnista, M. Sc., Doutoranda em Ciência Animal, Universidade Estadual de Londrina, Londrina, Paraná; \\ ${ }^{6}$ Zootecnista, D. Sc., Bolsista de Pós-doutorado, PNPD Institucional CAPES/UFGD; \\ ${ }^{7}$ Méd. Vet., Mestranda em Zootecnia-UFGD \\ *E-mail para correspondência - gustavo353@hotmail.com
}

RESUMO. O entendimento do crescimento e desenvolvimento animal e seus efeitos na composição regional e tecidual são determinantes para o aperfeiçoamento da produção de carne ovina. Sabe-se que o crescimento e desenvolvimento são regulados hormonalmente e controlados por leis fisiológicas e são influenciados por fatores genéticos e outros como o porte, a maturidade, o sexo, o manejo alimentar, a idade e o meio ambiente em que o animal está inserido. O estudo da composição regional ou anatômica se realiza mediante a separação da carcaça em cortes específicos, na revisão serão abordados a paleta e o pernil, por serem utilizados como referência pela facilidade e fidelidade na separação. A composição tecidual ou histológica dos cortes da carcaça é realizada pela técnica de dissecação que consiste na separação do corte em músculo, osso, gordura subcutânea, gordura intermuscular e outros tecidos (tendões, tecido conectivo, cartilagens, linfonodos). A literatura revisada demonstra uma grande variabilidade desses resultados, refletindo os diferentes sistemas de terminação, alimentação e grupamentos genéticos utilizados para a produção de carne ovina. A composição regional aliada à composição tecidual é um parâmetro utilizado para determinar a qualidade da carcaça ovina e o rendimento da porção comestível. Essas informações podem ser utilizadas em sistemas deavaliação de carcaça no sentido de valorizar as carcaças com maior percentual de carne e quantidade de gordura adequada ao mercado à que se destina.

Palavras-chave: Cordeiro, cortes, paleta, pernil, tecidos

\section{Evaluation of regional and tissue composition of lamb carcass}

\begin{abstract}
Understanding the animal growth and development and its effects on regional and tissue composition are crucial for improving the production of sheep meat. It is known that growth and development are regulated hormonally and controlled by physiological laws and are influenced by genetic and other factors such as size, maturity, sex, feeding regime, age and the environment in which the animal is inserted. The study of regional or anatomical composition is done by separating the carcass in specific cuts.In the review we discuss the shoulder and the leg, for use as reference by the ease and fidelity in separation. The tissue or histologic composition of carcass cuts is performed by dissection technique which consists in separating the cut on muscle, bone, subcutaneous fat, intermuscular fat and other tissues (tendons, connective tissue, cartilage, lymph nodes). The literature reviewed shows a great variability of these results, reflecting the different finishing systems, food and genetic groups used for the production of sheep meat. The regional composition combined with the tissue composition is a parameter used to determine the quality of the lamb carcass and edible portion yield. This information canbe used in carcass evaluation systems in order to enhance the carcasses with higher percentage of meat and appropriate amount of fat.
\end{abstract}

Key-words: cuts, lambs, leg, shoulder, tissues 


\section{Introdução}

A crescente demanda por proteína animal, registrada nos últimos anos, vem impulsionando o aperfeiçoamento na cadeia da ovinocultura de corte. A comercialização da carne de ovinos no Brasil, antes na forma de carcaça, atualmente predomina a oferta em forma de cortes comerciais, valorizando assim a porção comestível, principalmente pela sua qualidade nutricional e funcional (Osório et al., 2013, Vargas Júnior et al., 2013, Yamamoto et al., 2013).

Hashimoto et al. (2012) afirmaram que os estudos do crescimento e desenvolvimento são informações importantes para a eficiência da produção, uma vez que, conhecendo o ritmo de crescimento das regiões e dos tecidos que compõem a carcaça, será possível determinar com maior precisão o melhor momento de abate para cada grupo genético, favorecendo a padronização e a qualidade do produto ofertado.

Outra prática de padronização é a separação da carcaça em cortes comerciais, que serve para dividi-la em regiões de acordo com a preferência do consumidor, que difere entre países e dentro de um mesmo país ou região, dependendo do tipo de carcaça, costumes culinários e deve permitir o melhor aproveitamento possível da carcaça (Cañeque \& Sañudo, 2005, Osório \& Osório, 2005, Panea et al., 2012).

Mas, a qualidade para o consumidor está em sua porção comestível, relação entre o músculo e gordura; sendo a composição tecidual obtida pela dissecação dos cortes da carcaça, processo que envolve a separação em músculo, gordura subcutânea e intermuscular, osso e outros tecidos. Portanto, o conhecimento da composição regional e tecidual da carcaça é fundamental, pois pode auxiliar na diferenciação dos seus preços (Cezar \& Sousa, 2007, Moreno et al., 2010 Osório et al., 2013,).

Na busca da padronização, a terminação de cordeiros em confinamento passou a ter grande destaque em função dos aspectos econômicos e qualitativos da carcaça e da carne. Portanto, trabalhar com animais jovens que respondam as condições do sistema produtivo é uma boa estratégia, ou seja, produzir carcaças que propiciem cortes com maior quantidade de músculo, proporção ideal de gordura e mínima de osso é essencial, além de focar na qualidade organoléptica desejada (Zanette \& Neumann, 2012, Alves, 2013).

Com ênfase nos pontos acima expostos, esta revisão objetivou discorrer sobre o crescimento e desenvolvimento animal e seus efeitos na composição regional e tecidual (da paleta e pernil) a partir de pesquisas sobre características quantitativas e qualitativas na carcaça ovina.

\section{Crescimento e desenvolvimento animal}

Em qualquer sistema produtivo o entendimento da fisiologia é importante para a exploração animal. Os animais sofrem transformações constantes desde o momento de sua concepção até sua morte, e as mudanças que ocorrem entre a fecundação e a maturidade, estão estreitamente relacionadas com os fenômenos de crescimento e desenvolvimento. Estes dois processos são básicos para a produção de carne, podendo ser estudados isoladamente ou não (Berg \& Walters, 1983, Azeredo et al., 2005).

De acordo com Carlson (1972) o crescimento é definido como decorrência do aumento relativo da massa orgânica total, procedente de um incremento de tamanho dos tecidos e órgãos individuais. $\mathrm{O}$ crescimento consiste em um incremento do tamanho do ser vivo pelo aumento do volume e do número de suas células. Entretanto, Sobrero (1986) vai além e diz que o crescimento é uma forma de produzir carne, que inicia na prenhez da fêmea e finaliza na maturidade fisiológica do indivíduo (largura, comprimento e altura do corpo do animal) e que incluem peso. Assim, entende-se por crescimento as mudanças operadas na magnitude do animal, até que o mesmo atinja o seu estado adulto.

Analisando as leis que regem o crescimento relativo nos ovinos, Hammond \& Mas (1966) indicaram que existem duas ondas de crescimento no organismo, disto-proximal e anteroposterior. Ambas reúnem-se na zona dorsolombar (união entre a região do lombo e a última costela) na região com desenvolvimento mais tardio. 
Com relação à definição de desenvolvimento, as elucidações são semelhantes Hammond \& Mas (1966) definiram como sendo a modificação da conformação corporal do animal até que suas diversas funções alcancem a plenitude. Beranger \& Robelin (1977) afirmaram que o desenvolvimento é algo mais que um aumento de tamanho, já que um carneiro não é uma versão aumentada de um cordeiro. Butterfield (1966) descreve como mudanças na forma e nas proporções corporais associadas ao crescimento.

Portanto, o crescimento e desenvolvimento são regulados hormonalmente, de forma que, para obter-se um crescimento normal é necessário que o sistema endócrino esteja em perfeito funcionamento. No entanto, estes processos são controlados por leis físiológicas e são influenciados por fatores genéticos e outros como o porte, a maturidade, o sexo, o manejo alimentar, a idade e o meio ambiente que circunda o animal (Espejo-Diaz \& ColomerRocher, 1971, Colomer-Rocher et al., 1987, Osório et al., 2001).

Butterfield (1966) afirmaram que o padrão de desenvolvimento dos órgãos de ovinos; quando a ingestão de alimentos não é restringida, após o nascimento é maior para o cérebro, intestino, fígado, coração e músculos do que para o peso corporal. Tulloh et al. (1986) constataram que quando a ingestão de alimentos e restringida, particularmente no período anterior a $30 \%$ da maturidade, a proporção de alguns órgãos com intestino, fígado e músculos podem ter suas dimensões reduzidas.

Dentre os fatores que influenciam no crescimento e desenvolvimento, a eficiência do processo de produção da carne ovina depende do desempenho reprodutivo das ovelhas, tendo como elemento central o cordeiro, cuja velocidade de crescimento é determinada basicamente pela qualidade do alimento ingerido. Sendo que até a puberdade os efeitos do plano nutricional sobre o desenvolvimento têm grande importância devido às suas relações com a produção econômica de carne (Furusho-Garcia et al., 2006, Gonzaga Neto et al., 2006, Almeida et al., 2009).

Quanto ao crescimento e desenvolvimento dos cortes comerciais, Osório \& Osório (2005) afirmaram que a paleta, o pernil e o pescoço apresentam desenvolvimento precoce ou semelhante ao peso corporal, enquanto as costelas e o lombo apresentam desenvolvimento mais lento ou tardio.

Em relação à escala de deposição dos tecidos no animal, segue uma ordem gradativa: osso, músculo, gordura visceral, gordura intermuscular, gordura subcutânea e a gordura intramuscular (marmoreio). A velocidade e o ímpeto de deposição dos tecidos podem sofrer efeito dos fatores intrínsecos que o animal foi submetido (Hammond \& Mas, 1966, Osório et al., 2002, Rosa et al., 2005).

A identificação de fases do desenvolvimento em que intervenções estratégicas podem ser feitas para melhorar a deposição dos tecidos corporais. Portanto, o entendimento da escala de deposição dos tecidos na carcaça em relação ao peso corporal ao abate é fundamental (Tabela 1).

Tabela 1. Peso dos tecidos muscular, ósseo e adiposo em função do peso corporal ao abate na espécie ovina

\begin{tabular}{lccccccccccc}
\hline & \multicolumn{10}{c}{ Peso corporal ao abate $(\mathrm{kg})$} \\
\cline { 2 - 13 } Tecido & 4 & 10 & 20 & 30 & 40 & 50 & 60 & 70 & 80 & 9 & 100 \\
\hline Músculo & 1,1 & 2,8 & 5,4 & 7,9 & 10,4 & 12,7 & 14,9 & 16,9 & 18,9 & 20,8 & 22,5 \\
Osso & 0,4 & 1,0 & 1,4 & 2,1 & 2,7 & 3,3 & 3,8 & 4,3 & 4,8 & 5,2 & 5,5 \\
Gordura & 0,1 & 0,4 & 1,1 & 2,3 & 3,9 & 5,8 & 8,2 & 11,0 & 14,2 & 17,8 & 21,8 \\
\hline
\end{tabular}

Fonte: Adaptado de Butterfield (1966).

Osório et al. (1995) verificaram que a composição regional varia de acordo com o grupo genético, devendo os cortes da carcaça que diferir entre si, ser comercializado separadamente e buscado o peso ótimo econômico de sacrifício desses grupos de animais (considerando os efeitos de grupo genético e sexo), em função do mercado comercial. Portanto, são a raça e o sexo 
fatores de variação importantes a serem considerados na padronização de cortes. O que foi corroborado por Roque et al. (1999) que estudando o desenvolvimento de cinco genótipos, verificaram que cada genótipo e/ou grupo de genótipos apresenta seu peso ótimo econômico de abate.

\section{Composição regional ou anatômica da carcaça}

O estudo da composição regional se realiza mediante a utilização da separação da carcaça em cortes específicos. É a ação de dividir determinadas partes anatômicas da carcaça estabelecidas por interesses comerciaise padronização.

A utilização de cortes comerciais, associados à apresentação do produto, proporciona a obtenção de preços diferenciados para as diversas partes da carcaça, além de permitir um aproveitamento mais racional com um mínimo de desperdício (Sañudo \& Sierra, 1986, Huidobro \& Cañeque, 1994, Osório \& Osório, 2005, Cezar \& Sousa, 2007).

Silva Sobrinho \& Silva (2000), Panea et al. (2012) afirmaram que, em teoria, as regiões anatômicas separadas deveriam integrar grupos musculares homogêneos com qualidade similar e preparação culináriaidêntica. De acordo com Jardim et al. (2007), Hashimoto et al. (2012) a separação regional da carcaça apresenta uma contribuição importante no melhoramento da qualidade da carne em ovinos, tanto no aproveitamento, quanto na uniformização da qualidade.

As exigências do consumidor moderno estão relacionadas ao peso mínimo ou máximo dos cortes ou da carcaça, desta forma, a qualidade do produto (Carvalho, 2002). Mas, antes de ser um inconveniente, a variabilidade dos cortes e carcaça são extremamente positivos por permitir atender as diferentes preferencias do mercado.

Diversos tipos de carcaças podem encontrar consumo garantido de acordo com o modo que será apreciado, inclusive aquelas carcaças de raças não tradicionalmente produtoras de carne (Oliveira et al., 2002, Almeida Júnior et al., 2004, Rodrigues et al., 2006). No entanto, existem cortes que propiciam um melhor aproveitamento para carcaças leves e outros para carcaças pesadas (Osório \& Osório, 2005).

No Brasil, as carcaças ovinas são tradicionalmente separadas em quatro partes: pescoço, costilhar, paleta e pernil (Osório \& Osório, 2005, Cezar \& Sousa, 2007). No entanto, ocostilhar pode sofrer subdivisões que permite melhor aproveitamento culinário e homogeneidade na qualidade dos cortes.

Silva Sobrinho (2001) define a divisão da carcaça em pescoço, paleta, costelas, lombo e pernil. Santos \& Pérez (2000) divide a carcaça em braço inferior, paleta, braço posterior, pernil, costeleta, lombo, costela/fralda e pescoço. Cañeque \& Sañudo (2005) divide a carcaça em pescoço, paleta, pernil, costelas fixas ou costelas verdadeiras, costelas flutuantes ou costelas falsas, lombo com vazio, baixo ou peito e cola.

Araújo Filho et al. (2007) separa a carcaça nos seguintes cortes comerciais: filé, contrafilé, paleta, pernil, picanha, carré, pescoço desossado. Monte et al. descreveram cortes para caprinos, adaptado para ovinos por Pompeu et al. (2013) em seis cortes: paleta, pernil, lombo (anterior e posterior), peito, costela e fraldinha.

Além dos nomes dos cortes popularmente conhecidos, estes podem apresentar outra nomenclatura, ou seja, o costume local imprime sua marca e suas peculiaridades (Carvalho, 2002). Neste sentido, no Rio Grande do Sulfoi criada uma marca de qualidade, Cordeiro Herval Premium, através de cortes específicos garantindo um produto padronizado ao consumidor (Osório et al., 2009, Esteves et al., 2013).

Isto não ocorre somente no Brasil, na Espanha, por exemplo, apesar das tentativas de uma normativa, em nível comercial, da separação da carcaça em cortes, nunca conseguiram colocar em prática e, em cada estabelecimento são realizadas separações, cortes, distintos em função do mercado e da época do ano. No trabalho realizado na Espanha Vergara \& Gallego (2000) dividem a carcaça nos seguintes cortes: pescoço, paleta, pernil, costilhar, baixo com fraldinha e rabo.

$\mathrm{Na}$ França, especificamente na região de Paris, existem subdivisões da carcaça com cortes 
específicos que agregam valor ao produto final. Obtêm-se cortes como pernil, sela, lombo, costelas com pé, costelas do fundo, paleta, peito e pescoço (Boccard \& Dumont, 1955).

Estes cortes, por sua vez, podem ser seccionados originando outros de mais fácil utilização na culinária doméstica. Tal procedimento origina produtos diferenciados que podem vir a satisfazer necessidades de consumidores mais exigentes quanto à qualidade e à forma de apresentação do produto a ser consumido (Osório \& Osório, 2005).

$\mathrm{Na}$ Argentina, utilizam os cortes praticados pela Junta Nacional de Carnes Argentina, como é o caso do costilhar duplo com osso de 6 a 7 costelas, que é realizado na carcaça inteira ou costilhar com osso de 6 a 7 costelas que é realizado na meia carcaça.

Entre os cortes, o pernil, lombo e costilhar são considerados cortes de primeira, a paleta corte de segunda, o baixo ou peito, pescoço e rabo são considerados corte de terceira (Vergara et al., 2005). ROSA et al. (2002) reforçam a ideia que a composição ideal da carcaça é aquela em que há um maior rendimento de cortes de primeira categoria.Mas, a valorização depende da preferência do mercado.

O pernil é considerado o mais nobre da carcaça ovina, por encontrar-se nele a maior massa muscular e o maior rendimento da porção comestível, portanto, sendo responsável por grande parte do valor econômico da carcaça (Silva Sobrinho, 2001, Araújo Filho et al., 2007).

$\mathrm{O}$ pernil e a paleta juntos representam mais de $50 \%$ do peso da carcaça, por esta razão as análises quantitativas e qualitativas são feitas nestes cortes por sua grande representatividade e correlação com toda carcaça (Cañeque \& Sañudo, 2005, Osório \& Osório, 2005, Cezar \& Sousa, 2007).

O conhecimento dos pesos e rendimentos dos principais cortes da carcaça permitea interpretação do desempenho animal (Jardim et al., 2007). A descrição dos pesos e rendimentos da paleta e do pernil encontrados emdiversos trabalhos que utilizaram metodologias semelhantes para os cortes são apresentados a seguir (Tabela 2).
Quando o peso dos cordeiros é similar, o rendimento dos componentes regionais é semelhante (Fernandes et al., 2010).

Barros et al. (2009), Ribeiro et al. (2009) encontraram maiores valores dos cortes em quilograma e porcentagem em animais terminados em confinamento em relação aos mantidos em pastagens.

Os valores médios, em kg e \%, são de ovinos procedentes de diferentes raças, sistemas de produção e terminação, idade e sexo; mas, independente desses fatores, tanto em $\mathrm{kg}$ como em $\%$, a paleta mostra de maneira consistente apresentar menores valores que o pernil. Isso mostra que o peso não pode ser critério de valorização dos cortes e que a porcentagem é critério mais idôneo.

Porém, existem critérios de escolhapelo consumidor, pela qual se rege a oferta e a demanda, cuja importância relativa é o fator primordial no estabelecimento do preço. É o caso, por exemplo, da composição tecidual da carcaça (Osório et al., 2007) e especialmente a porção comestível e razão músculo:gordura.

\section{Composição tecidualou histológica dos cortes}

A qualidade da carcaça depende da quantidade e proporções dos distintos tecidos e da relação existentes entre eles. Portanto, a carcaça ideal seria aquela onde a proporção de músculo é máxima, a de osso mínima e a de gordura adequada às exigências do mercado consumidor ao qual se destina (Carvalho et al., 2006, Santos et al., 2009, Osório \& Osório, 2005).

Neste contexto, a meta é a obtenção de animais capazes de direcionar grandes quantidades de nutrientes para a produção de músculos, uma vez que o acúmulo desse tecido é desejável e reflete maior parte da porção comestível de uma carcaça (Siqueira et al., 2010, Osório et al., 2013, Yamamoto et al., 2013).

Osório et al. (2002) afirmaram quea gordura apresenta papel importante na qualidade e na conservação da carne - os depósitos de gordura intermuscular, subcutâneo e intramuscular influem diretamente na maciez e suculência, uma vez que com o aumento das gorduras 
intermuscular e intramuscular ocorre maior sensação destas no ato mastigatório; e, com aumento da gordura subcutânea, diminui o risco de encurtamento pelo frio.

Tabela 2. Dados dos pesos $(\mathrm{kg})$ e rendimentos $(\%)$ da paleta e pernil de acordo com valores encontrados na literatura

\begin{tabular}{|c|c|c|c|c|}
\hline \multicolumn{2}{|c|}{ Paleta } & \multicolumn{2}{|c|}{ Pernil } & \multirow[b]{2}{*}{ Autores } \\
\hline Peso $^{1}$ & Rendimento $^{2}$ & Peso $^{T}$ & Rendimento $^{2}$ & \\
\hline 1,122 & 20,24 & 2,048 & 36,73 & Osório et al. (1999) $)^{3}$ \\
\hline 1,239 & 20,23 & 2,282 & 37,08 & Osório et al. (1999) ${ }^{4}$ \\
\hline 1,408 & 19,96 & 2,443 & 34,29 & Osório et al. $(2002)^{5}$ \\
\hline 1,415 & 21,13 & 2,379 & 35,56 & Osório et al. $(2002)^{6}$ \\
\hline 1,349 & 17,98 & 2,381 & 31,72 & Jardim et al. $(2007)^{7}$ \\
\hline 1,213 & 18,44 & 2,114 & 32,16 & Jardim et al. $(2007)^{8}$ \\
\hline 1,180 & 18,94 & 2,174 & 34,92 & Jardim et al. $(2007)^{9}$ \\
\hline 1,271 & 18,60 & 2,275 & 32,30 & Jardim et al. $(2007)^{10}$ \\
\hline 1,224 & 18,26 & 2,171 & 32,40 & Jardim et al. $(2007)^{11}$ \\
\hline 1,690 & 20,73 & 2,810 & 34,47 & Mendonça et al. (2008) $)^{12}$ \\
\hline 1,380 & 20,40 & 2,430 & 35,74 & Mendonça et al.(2008) $)^{13}$ \\
\hline 1,470 & 20,19 & 1,769 & 36,52 & Martins et al.(2008) \\
\hline 1,467 & 20,20 & 2,247 & 31,12 & Piola Junior et al. (2009) \\
\hline 1,390 & 18,02 & 2,410 & 31,50 & Siqueira et al. (2010) \\
\hline 1,420 & 18,65 & 2,785 & 36,50 & Moreno et al. (2010) \\
\hline 1,830 & 21,15 & 3,103 & 36,02 & Ribeiro et al. (2009) \\
\hline 1,426 & 18,07 & 2,310 & 29,22 & Cartaxo et al. (2011) \\
\hline 1,438 & 19,18 & 2,573 & 34,67 & Alves (2013) \\
\hline 1,456 & 18,84 & 2,676 & 34,71 & Santos et al. (2013) \\
\hline 1,840 & 19,26 & 3,123 & 32,56 & Lima et al. (2013) \\
\hline 3,120 & 20,17 & 5,622 & 36,27 & Carvalho et al. (2014) \\
\hline 1,317 & 16,42 & 2,470 & 30,97 & Moura Neto et al. (2014) \\
\hline
\end{tabular}

${ }^{1}$ Peso em (kg); ${ }^{2}$ Rendimento (\%); ${ }^{3}$, Osório et al. (1999) - cordeiros castrados e inteiros; ${ }^{5,6}$ Osório et al. (2002) cordeiros oriundos de cruzamentos Border Leicester x Ideal e Border Leicester x Corriedale; ${ }^{7,8,9,10,11}$ Jardim et al. (2007) - cordeiros com 120, 210, 360 dias, inteiros e castrados, respectivamente; ${ }^{12,13}$ Mendonça et al. (2008) época de nascimento cordeiros, Agosto e Novembro, respectivamente.

A determinação da composição tecidual dos cortes da carcaça é de fundamental importância, realizada através da técnica de dissecação, que consiste na separação do corte em músculo, osso, gordura subcutânea, gordura intermuscular e outros componentes (Moreno et al., 2010).

O conhecimento prévio dos componentes teciduais e sua localização no corte anatômico são necessários para realização da dissecação. A gordura subcutânea localizada imediatamente sob a pele, gordura intermuscular localizada abaixo da fáscia profunda, associada aos músculos; músculo:musculatura do corte mecanicamente separada da sua base óssea, bem como do conteúdo de gordura intermuscular, gordura subcutânea e outros; osso:base óssea de cada corte livre de qualquer outro tecido: outros tecidos:tecidos não identificados, compostos por tendões, glândulas, nervos e vasos sanguíneos (Osório \& Osório, 2005).

A ordem de separação dos componentes teciduais tende iniciar com a retirada de toda a gordura subcutânea do corte, em seguida, da gordura intermuscular, músculo, outros tecidos, e por último a desarticulação dos ossos e sua raspagem para retirada de tecidos que ficaram aderidos.

A separação da gordura durante a dissecação é dificultosa, o que gera altos coeficientes de variação para o peso e rendimento (Cezar \& Souza, 2007). Contudo, temsido utilizada de maneira confiável a informação da gordura total, através do somatório da gordura subcutânea e gordura intermuscular. 
De modo geral adissecação de toda a carcaça ou da meia carcaça apenas se justifica em casos especiais, por ser lenta, trabalhosa e onerosa. Sendo mais comum a dissecação dos principais cortes comerciais, paleta e/ou pernil, por apresentarem alto coeficiente de correlação com a composição total da carcaça e constituírem, juntos, mais de $50 \%$ da carcaça ovina (Osório \& Osório, 2005, Cezar \& Sousa, 2007, Panea et al., 2012).

No entanto, a partir deste cenário torna-se necessário também o entendimento da composição tecidual dos demais cortes comerciais, pois representa outra fração significativa da carcaça, e atendem a preferência de diferentes mercados consumidores e constituem diferentes valores econômicos.

As informaçõesdescritas nas Tabelas 3, 4 e 5 foram obtidas em trabalhos que avaliaram a composição tecidual de cortes comerciais de cordeiros eutilizaram a metodologia de dissecação descrita por Osório \& Osório (2005).

$\mathrm{Na}$ tabela 3, estão descritos os valores encontrados na literatura do peso e rendimento do músculo, gordura total e osso em relação à composição tecidual da paleta. Pelos valores de peso e rendimento, percebe-se que o único componente tecidual que apresentou grande variação foi à gordura entre os trabalhos avaliados.

Tabela 3. Peso $(\mathrm{kg})$ e rendimento $(\%)$ do músculo, gordura total, osso em relação à composição tecidual da paleta

\begin{tabular}{|c|c|c|c|}
\hline Paleta (Tecidos) & Peso $^{1}$ & Rendimento $^{2}$ & Autores \\
\hline Músculo & 0,630 & 46,50 & \\
\hline Gordura Total $^{3}$ & 0,247 & 17,77 & Jardim et al. $(2007)^{4}$ \\
\hline Osso & 0,327 & 24,26 & \\
\hline Músculo & 0,535 & 44,31 & \\
\hline Gordura Total $^{3}$ & 0,197 & 16,12 & Jardim et al. $(2007)^{5}$ \\
\hline Osso & 0,309 & 25,65 & \\
\hline Músculo & 0,570 & 48,18 & \\
\hline Gordura Total $^{3}$ & 0,137 & 11,59 & Jardim et al. $(2007)^{6}$ \\
\hline Osso & 0,323 & 27,53 & \\
\hline Músculo & 0,578 & 45,50 & \\
\hline Gordura Total $^{3}$ & 0,196 & 15,23 & Jardim et al. $(2007)^{7}$ \\
\hline Osso & 0,323 & 25,57 & \\
\hline Músculo & 0,575 & 47,05 & \\
\hline Gordura Total $^{3}$ & 0,190 & 15,04 & Jardim et al. $(2007)^{8}$ \\
\hline Osso & 0,316 & 26,16 & \\
\hline Músculo & 0,725 & 53,83 & \\
\hline Gordura Total $^{3}$ & 0,271 & 20,47 & Klein Júnior et al. (2008) \\
\hline Osso & 0,277 & 20,45 & \\
\hline Músculo & 0,766 & 55,46 & \\
\hline Gordura Total $^{3}$ & 0,190 & 13,58 & (Alves, 2013) \\
\hline Osso & 0,294 & 21,29 & \\
\hline Músculo & 0,870 & 53,15 & \\
\hline Gordura Total $^{3}$ & 0,295 & 17,80 & Catalano Neto (2012) \\
\hline Osso & 0,327 & 20,14 & \\
\hline
\end{tabular}

A gordura é o componente da carcaça que apresenta maior variação, sendo influenciado principalmente pelo genótipo e pelo sistema de terminação, em que raças mais precoces e sistemas nutricionais mais elevados tendem a originar carcaças com maior deposição de gordura (Rosa et al., 2005, Almeida et al., 2006, Gonzaga Neto et al., 2006).

De acordo com Osório et al. (2002) a variação relativa das percentagens de músculo e gordura 
são importantes, porém a variabilidade quantitativa do tecido adiposo e sua qualidade é a mais importante da carcaça, sendo que as variações da proporção de músculo estão associadas com as variações da proporção de gordura da carcaça.

Na tabela 4, estão descritos os valores do peso e rendimento do músculo, gordura total e osso em relação à composição tecidual do pernil. Para a composição tecidual deste corte pode-se observarvariação para peso e rendimentodo componente músculo.

Osório et al. (2002) a velocidade de crescimento dos músculos é semelhante a do peso corporal. No entanto, as diferenças encontradas nos trabalhos para peso e rendimento de músculo pode ter ocorrido pelo efeito do genótipo, idade e/ou dieta.

$\mathrm{Na}$ Tabela 5, estão descritos os valores das razões teciduais músculo:gordura e músculo:osso da paleta e do pernil.Santos \& Pérez (2000) constaram que o pernil e a paleta foram os cortes que apresentaram melhores razões músculo:osso e músculo:gordura, os valores foram satisfatórios com peso corporal ao abate entre 25 e $35 \mathrm{~kg}$. Furusho-Garcia et al. (2006) avaliaram a relação tecidual de cordeiros abatidos com 15, 25, 35 e $45 \mathrm{~kg}$ e observaram valores crescentes de músculo:osso da meia carcaça ou do pernil, à medida que aumentava o peso de abate

Tabela 4. Peso $(\mathrm{kg})$ e rendimento $(\%)$ do músculo, gordura total, osso em relação à composição tecidual dopernil

\begin{tabular}{|c|c|c|c|}
\hline Pernil (Tecidos) & Peso $^{1}$ & Rendimento $^{2}$ & Autores \\
\hline Músculo & 1,210 & 49,13 & \\
\hline Gordura total ${ }^{3}$ & 0,297 & 12,16 & Jardim et al. $(2007)^{4}$ \\
\hline Osso & 0,665 & 27,67 & \\
\hline Músculo & 0,998 & 47,34 & \\
\hline Gordura total ${ }^{3}$ & 0,210 & 9,73 & Jardim et al. $(2007)^{5}$ \\
\hline Osso & 0,606 & 25,59 & \\
\hline Músculo & 1,130 & 52,09 & \\
\hline Gordura total $^{3}$ & 0,157 & 7,26 & Jardim et al. $(2007)^{6}$ \\
\hline Osso & 0,611 & 28,41 & \\
\hline Músculo & 1,131 & 49,55 & \\
\hline Gordura total $^{3}$ & 0,222 & 9,52 & Jardim et al. $(2007)^{7}$ \\
\hline Osso & 0,626 & 27,40 & \\
\hline Músculo & 1,081 & 49,54 & \\
\hline Gordura total $^{3}$ & 0,210 & 9,56 & Jardim et al. $(2007)^{8}$ \\
\hline Osso & 0,625 & 27,07 & \\
\hline Músculo & 1,382 & 66,82 & \\
\hline Gordura total ${ }^{3}$ & 0,242 & 11,41 & Fernandes et al. (2010) \\
\hline Osso & 0,443 & 21,44 & \\
\hline Músculo & 1,944 & 67,89 & \\
\hline Gordura Total $^{3}$ & 0,559 & 12,68 & Nóbrega et al. (2013) \\
\hline Osso & 0,366 & 19,44 & \\
\hline Músculo & 1,452 & 59,30 & \\
\hline Gordura total ${ }^{3}$ & 0,304 & 12,38 & Alves et al. (2013) \\
\hline Osso & 0,487 & 19,85 & \\
\hline Músculo & 1,532 & 57,34 & \\
\hline Gordura total ${ }^{3}$ & 0,360 & 14,17 & Catalano Neto (2012) \\
\hline Osso & 0,562 & 20,95 & \\
\hline
\end{tabular}

${ }^{1}$ Peso (kg); ${ }^{2}$ Rendimento (\%); ${ }^{3}$ Gordura Total (somatório da gordura subcutânea e gordura intermuscular); 4,5,6,7,8 JARDIM et al. (2007) - cordeiros com 120, 210, 360 dias, inteiros e castrados, respectivamente

Verifica-se que a porção comestível da paleta possui maisgordura que a do pernil (Tabela 5); aspecto a considerar no preparo desses cortes e que pode ser utilizado para atender a 
consumidores que preferem mais ou menos gordura. Hoje é necessário informar e saber o que deseja o consumidor. Para isso, os painéis sensoriais, painel de catadores e confraria de consumidores de carne ovina podem auxiliar dizendo as preferências deste ou daquele mercado, desta maneira, pode-se chegar à reazão músculo:gordura para cada mercado e/ou perfil de consumidores.

Fernandes et al. (2010) encontraram efeito significativo dos sistemas de alimentação sobre a razão músculo:gordura de cordeiros abatidos aos 3 e 4 meses de idade. Além disso, notou-se efeito nas condições de acabamento e de conformação das carcaças, em função dos sistemas alimentares de terminação dos cordeiros.

Osório et al. (2002); Cezar \& Sousa (2010) constataram que uma maior relação músculo: osso e uma menor relação músculo: gordura é fundamental do ponto de vista do consumidor, já que o músculo é o tecido mais valorizado da carcaça, sendo tal relação observada nas raças mais especializadas na produção de carne, de maior porte e mais tardias.

Osório et al. (2007) afirmaram que um exemplo simples de antagonismo da qualidade na cadeia produtiva é valorização comercial pelo peso, ou seja, quando as carcaças mais pesadas são mais valorizadas, paga-se mais por $\mathrm{kg}$. Entretanto, com aumento de peso há também aumento do engorduramento e, gordura em excesso não interessa ao açougueiro, pois, além do trabalho de toalete para retirada dessa, o preço recebido é inferior ao que foi pago pela carcaça. Da mesma forma, o custo de produção da gordura é maior do que para produção de músculo. No entanto, para cada raça ou sistema de terminação e alimentação adotado existe um parâmetro a ser levado em consideração para o critério de abate, a fim de estimar o momento desejado do ímpeto de deposição tecidual.

Tabela 5. Razões teciduais músculo:gorduraemúsculo:ossoda paleta e pernil de cordeiros

\begin{tabular}{llll}
\hline Relações teciduais & Paleta & Pernil & \multicolumn{1}{c}{ Autores } \\
\hline & 3,60 & 4,40 & Santos \& Pérez et al. (2000) \\
& 3,02 & 4,35 & Pilar (2002) \\
& 2,55 & 4,07 & Jardim et al. (2007) \\
& 2,71 & 4,75 & Jardim et al. $(2007)^{4}$ \\
& 4,16 & 7,20 & Jardim et al. $(2007)^{5}$ \\
Músculo:Gordura $^{1}$ & 2,95 & 5,09 & Jardim et al. $(2007)^{6}$ \\
& 3,02 & 5,15 & Jardim et al. (2007) \\
& 3,34 & 5,47 & Mendonça et al.(2008) \\
& 4,92 & 10,96 & Mendonça et al.(2008) \\
& 3,80 & 6,36 & Piola Júnior et al.(2009) \\
& 4,39 & 5,15 & Alves (2013) \\
& 3,17 & 4,41 & Catalano Neto (2012) \\
\hline & 3,60 & 4,00 & Santos \& Pérez (2000) \\
Músculo:Osso $^{2}$ & 3,40 & 4,35 & Pilar (2002) \\
& 2,18 & 2,62 & Mendonça et al. (2008) \\
& 2,58 & 3,16 & Mendonça et al. (2008) \\
& 3,56 & 4,66 & Piola Júnior et al. (2009) \\
& 2,62 & 3,01 & Alves (2013) \\
& 2,65 & 2,75 & Catalano Neto (2012) \\
\hline
\end{tabular}

${ }^{1}$ Músculo:Gordura= Peso do Músculo: Peso de Gordura Total (intermuscular e subcutânea); ${ }^{2}$ Músculo:Osso= Peso do músculo: Peso de Osso; ${ }^{3,4,5,6,7}$ Jardim et al. (2007)- cordeiros com 120, 210, 360 dias, inteiros e castrados, respectivamente; ${ }^{10,11}$ Mendonça et al. (2008) - época de nascimento cordeiros, Agosto e Novembro, respectivamente

Diversos pesquisadores já vêm a alguns anos trabalhando com a avaliação da condição corporal como critério de abate (Osório \& Osório, 2005; Esteves et al., 2010) encontraram alta relação entre a condição corporal e o estado de engorduramento da carcaça. Portanto, a avaliação da condição corporal como critério de abate é importante para nortear o ponto ideal de 
abate do animal e torna-se fundamental para o processo produtivo da carne. Entretanto, a associação com outras ferramentas de avaliação in vivo é capaz de potencializar os resultados obtidos.

\section{Considerações finais}

A escolha da categoria animal, sistema de terminação e alimentação influi nas características avaliadas.

O conhecimento prévio do crescimento e desenvolvimento animal é atributo fundamental para entendimento da composição regional e tecidual.

A composição regional aliada à composição tecidual éum parâmetro utilizado para determinar a qualidade da carcaça ovina.

O sistema de avaliação de carcaça deve abarcar uma enorme variabilidade e sabendo que a porção comestível, relação músculo: gordura e sua composição química devem prevalecer na valorização comercial.

A carcaça mais valorizada deve ser a que tenha a porção comestível que satisfaça e cause os maiores benefícios após a digestão.

\section{Refências bibliográficas}

Almeida, C. H. S. L.; Galvani, C. P.; Diego, B.; Hastenpflug, R. F. d. L. M. \& Gasperin, B. G. 2006. Características de carcaça de cordeiros Ideal e cruzas Border Leicester X Ideal submetidos a três sistemas alimentares. Ciência Rural, 36, 1542-1546.

Almeida Júnior, G. A.; Costa, C.; Monteiro, A. L. G.; Garcia, C. A.; Munari, D. P. \& Neres, M. A. 2004. Qualidade da carne de cordeiros criados em creep feeding com silagem de grãos úmidos de milho. Revista Brasileira de Zootecnia, 33, 1039-1047.

Almeida, T.; Pérez, J.; Paula, O.; França, P.; Macedo Júnior, G. \& Assis, R. 2009. Efeito do nível de energia metabolizável na composição dos tecidos da carcaça de cordeiros da raça Santa Inês. Arquivo Brasileiro de Medicina Veterinaria e Zootecnia, 61, 1364-1372.
Alves, L. G. C. 2013. Composição regional e tecidual de cordeiros terminados com dietas contendo grão de soja in natura ou desatvado. Universisdade Federal da Grande Dourados.

Araújo Filho, J. T.; Costa, R. G.; Fraga, A. B.; Neto, S. G.; Pacheco, K. M. G. \& Rocha, L. P. 2007. Agregação de valor em carcaça de cordeiros deslanados por meio de cortes especiais. Revista Científica de Produção Animal, 9.

Azeredo, D. M.; Osório, M. T. M.; Osório, J. C. S.; Mendonça, G.; Barbosa, J. \& Esteves, R. 2005. Crescimento e desenvolvimento de ovinos Corriedale não castrados, castrados e criptorquidas abatidos com diferentes pesos. Revosta Brasileira de Agrociências, 11, 339345.

Barros, C. S.; Monteiro, A. L. G.; Candal, C. H. E.; Poli, J. R. D.; Canziani, J. R. F. \& Machado, M. A. 2009. Rentabilidade da produção de ovinos de corte em pastagem e em confinamento1. Revista Brasileira de Zootecnia, 38, 2270-2279.

Beranger, C. \& Robelin, J. 1977. Influence du mode d'élevage, de la sélection et de l'alimentation sur l'état d'engraissement des bovins. Annalles Biologie Animal Biochemie et Biophysiologie, 17, 905-921.

Berg, R. T. \& Walters, L. E. 1983. The meat animal: Changes and challenges. Journal of Animal Science, 57, 133-146.

Boccard, R. \& Dumont, B. 1955. Étude de la production de la viande chez les ovins. I. La coupe des carcasses. Définition d'une découpe de référence. Annales de Zootechnie, 3, 241257.

Butterfield, R. M. 1966. Relative growth in beef cattle. Australian Veterinary Journal, 42, 8790.

Cañeque, V. \& Sañudo, C. 2005. Estandarización de las metodologías para evaluar la calidad del producto (animal vivo, canal, carne y grasa) en los rumiantes. INIA, Zaragoza.

Carlson, J. 1972. Reguladores del crecimiento. In: Hafez, E. S. (ed.) Desarrollo y nutrición animal. Acribia, Zaragoza. 
Cartaxo, F. Q.; Sousa, W.; Costa, R. G.; Cezar, M. F.; Pereira Filho, J. \& Cunha, M. d. G. G. 2011. Características quantitativas da carcaça de cordeiros de diferentes genótipos submetidos a duas dietas. Revista Brasileira de Zootecnia, 40, 2220-2227.

Carvalho, P. A. 2002. Influência da restrição alimentar e do ganho compensatório sobre o crescimento, composição de carcaça e qualidade da carne de cordeiros da raça Santa Inês. Animal Science. Universidade Federal de Lavras, Lavras.

Carvalho, P. C. F.; Oliveira, J. O. R.; da Silveira Pontes, L.; da Silveira, E. O.; Poli, C. H. E. C.; Rübensam, J. M. \& Santos, R. J. 2006. Características de carcaça de cordeiros em pastagem de azevém manejada em diferentes alturas. Pesquisa Agropecuária Brasileira, 41, 1193-1198.

Carvalho, S.; Pires, C.; Macari, S.; Lopes, J.; Moro, A.; Venturini, R.; Lins, A. \& Teixeira, R. 2014. Características produtivas de cordeiros terminados em confinamento com dietas contendo diferentes teores de borra de soja. Arquivo Brasileiro de Medicina Veterinaria e Zootecnia, 66, 259-267.

Catalano Neto, A. P. 2012. Glicerina bruta na alimentação de cordeiros pantaneiros confinados. Animal Science. Universidade Federal da Grande Dourados, Dourados.

Cezar, M. \& Sousa, W. 2007. Carcaças ovinas e caprinas: obtenção, avaliação e classificação. Uberaba: Editora Agropecuária Tropical, 147.

Colomer-Rocher, F.; Morand-Fehr, P. \& Kirton, A. H. 1987. Standard methods and procedures for goat carcass evaluation, jointing and tissue separation. Livestock Production Science, 17, 149-159.

Espejo-Diaz, M. \& Colomer-Rocher, F. 1971. Influencia del estado de engrasamiento y la conformacion sobre el porcentaje de piezas de la canal ovina. Instituto Nacional de Investigación Agrarias, 1, 79-92.

Esteves, R. M. G.; Osório, J. C. d. S.; Osório, M. T. M.; Mendonça, G.; Oliveira, M. M.; Wiegand, M.; Vilanova, M. S.; Correa, F. \&
Jardim, R. D. 2013. Avaliação in vivo e da carcaça e fatores determinantes para $o$ entendimento da cadeia da carne ovina. Current Agricultural Science and Technology, 16.

Fernandes, M. A. M.; Monteiro, A. L. G.; Poli, C. H. E. C.; Barros, C. S.; Almeida, R. \& Ribeiro, T. M. D. 2010. Composição tecidual da carcaça e perfil de ácidos graxos da carne de cordeiros terminados a pasto ou em confinamento. Revista Brasileira de Zootecnia, 39, 1600-1609.

Furusho-Garcia, I. F.; Perez, J. R. O.; Bonagurio, S. \& Santos, C. 2006. Estudo alométrico dos cortes de cordeiros Santa Inês puros e cruzas. Revista Brasileira de Zootecnia, 35, 14161422.

Gonzaga Neto, S.; Silva Sobrinho, A. G.; Lopes, N. M. B.; Zeola, C. A. T. M.; Azevedo Silva, A. M.; Morais, J. \& Pereira Filho, Â. C. D. F. 2006. Características quantitativas da carcaça de cordeiros deslanados Morada Nova em função da relação volumoso: concentrado na dieta1. Revista Brasileira de Zootecnia, 35, 1487-1495.

Hammond, J. \& Mas, F. P. 1966. Principios de la explotación animal: reproducción, crecimiento y herencia. Acribia, Zaragoza.

Hashimoto, J. H.; Osório, J.; Osório, M.; Bonacina, M. \& Lehmen, R. I. P. 2012. Qualidade de carcaça, desenvolvimento regional e tecidual de cordeiros terminados em três sistemas. Revista Brasileira de Zootecnia, 41, 438-448.

Huidobro, R. F. \& Cañeque, V. 1994. Produccion de carne de corderos de raza Manchega. 5. Crecimiento relativo del quinto cuarto y de los tejidos y piezas de la canal. Investigacion Agraria: Produccion y Sanidad Animales, 9, 95-108.

Jardim, R. D.; Osório, J. C. S.; Osório, M. T. M.; Mendonça, G.; Del Pino, F. A. B.; Oliveira, M. M. \& Prediée, G. 2007. Composição tecidual e quimica da paleta com a perna em ovinos da raça Corriedale. Revista Brasileira de Agrociência, 13, 231-236. 
Lima, J. A. d.; Gavioli, I. L. d. C.; Barbosa, C. M. P.; Berndt, A.; Gimenes, F. M. d. A. \& Paz, C. C. d. P. 2013. Soybean silage and sugarcane tops silage on lamb performance. Ciência Rural, 43, 1478-1484.

Mendonça, G.; Osório, J. C. S.; Osório, M. T. M.; Silveira, I. D. B.; Gonçalves, M. \& Rocha, A. 2008. Época de nascimento sobre a composição regional e tecidual da carcaça de cordeiros da raça Texel. Revista Brasileira de Zootecnia, 37, 1072-1078.

Moreno, G.; Sobrinho, A. S.; Leão, A.; Loureiro, C. \& Perez, H. 2010. Rendimentos de carcaça, composição tecidual e musculosidade da perna de cordeiros alimentados com silagem de milho ou cana-de-açúcar em dois níveis de concentrado. Arquivo Brasileiro de Medicina Veterinária e Zootecnia, 62, 686-695.

Moura Neto, J. B.; Pereira, L. G. R.; Chizzotti, M. L.; Yamamoto, S. M.; Aragão, A. d. S. L. \& Santos Mascioli, A. 2014. Componentes constituintes e não constituintes da carcaça de cordeiros Santa Inês alimentados com farelo de manga em substituição ao milho. Semina: Ciências Agrárias, 35, 437-448.

Nóbrega, G. H.; Cézar, M. F.; Pereira Filho, J. M.; Sousa, W. H.; Sousa, O. B.; Cunha, M. G. G. \& Santos, J. R. S. 2013. Regime alimentar para ganho compensatório de ovinos em confinamento: composição regional e tecidual da carcaça. Arquivo Brasileiro de Medicina Veterinaria e Zootecnia, 65, 469-476.

Oliveira, M. V. M.; Pérez, J. R. O.; Alves, E. L.; Martins, A. R. V. \& Lana, R. d. P. 2002. Rendimento de carcaça, mensurações e peso de cortes comerciais de cordeiros Santa Inês e Bergamácia alimentados com dejetos de suínos em confinamento. Revista Brasileira de Zootecnia, 31, 1451-1458.

Osório, J.; Osório, M.; Oliveira, N. \& Siewerdt, L. 2002. Qualidade, morfologia e avaliação de carcaças, Pelotas.

Osório, J. C. d. S.; Osório, M. T. M.; Ávila, C. J. C.; Mendonça, G.; Wiegand, M. M.; Pedroso, C. E. \& Gonzaga, S. S. 2009. Sistema de produção de cordeiros-produção integrada/Herval Premium. PubVet, 3, 1-8.
Osório, J. C. S.; Conceição Jardim, P. O.; Pimentel, M. A.; Pouey, J.; Osório, M. T. M.; Lüder, W. E. \& Flávio, B. M. 1999. Produção de carne entre cordeiros castrados e não castrados: 1. Cruzas Hampshire Down X Corriedale. Ciência Rural, 29, 135-138.

Osório, J. C. S. \& Osório, M. T. 2005. Produção de carne ovina: técnicas de avaliação "in vivo" e na carcaça. Universidade Federal de Pelotas, Pelotas.

Osório, J. C. S.; Sierra, I.; Sañudo, C.; Maria, G. \& Osório, M. T. 1995. Estudio comparativo de la calidad de la canal en el tipo" ternasco" según procedencia. Current Agricultural Science and Technology, 1, 145-150.

Osório, M. T.; Downey, G.; Moloney, A. P.; Röhrle, F. T.; Luciano, G.; Schmidt, O. \& Monahan, F. J. 2013. Beef authentication using dietary markers: Chemometric selection and modelling of significant beef biomarkers using concatenated data from multiple analytical methods. Food Chemistry, 141, 2795-2801.

Osório, M. T.; Zumalacárregui, J. M.; Figueira, A. \& Mateo, J. 2007. Fatty acid composition in subcutaneous, intermuscular and intramuscular fat deposits of suckling lamb meat: Effect of milk source. Small Ruminant Research, 73, 127-134.

Osório, M. T. M.; Osório, J. C. d. S.; Jardim, R. D.; Oliveira, N. R. M. d. \& Pouey, J. L. O. F. 2001. Desenvolvimento de cordeiros da raça Corriedale criados em distintos sistemas. Revista Brasileira de Agrociência, 7, 46-49.

Panea, B.; Ripoll, G.; Horcada, A.; Sañudo, C.; Teixeira, A. \& Alcalde, M. J. 2012. Influence of breed, milk diet and slaughter weight on carcass traits of suckling kids from seven Spanish breeds. Spanish Journal of Agricultural Research, 10, 1025-1036.

Pilar, R. C. 2002. Desempenho, características de carcaça, composição e alometria dos cortes em cordeiros Merino Australiano e cruza Ile de France x Merino Australiano. Animal Science. Lavras.

Piola Junior, W.; Ribeiro, E. L. A.; Mizubuti, I. Y.; Silva, L. D. F.; Sousa, C. L. \& Paiva, F. H. 
P. 2009. Níveis de energia na alimentação de cordeiros em confinamento e composição regional e tecidual das carcaças. Revista Brasileira de Zootecnia, 38, 1797-1802.

Pompeu, R. C. F. F.; Beserra, L. T.; Cândido, M. J. D.; Bomfim, M. A. D.; Vieira, M. M. M. \& Andrade, R. R. 2013. Características da carcaça e dos componentes não-carcaça de ovinos alimentados com dietas contendo casca de mamona. Revista Brasileira de Saúde e Produção Animal, 14, 490-507.

Ribeiro, T. M. D.; Monteiro, A. L. G.; Poli, C.; Moraes, A.; Silva, A. L. P. \& Barros, C. S. 2009. Características da pastagem de azevém e produtividade de cordeiros em pastejo. Revista Brasileira de Zootecnia, 38, 580-587.

Rodrigues, S.; Cadavez, V. \& Teixeira, A. 2006. Breed and maturity effects on Churra Galega Bragançana and Suffolk lamb carcass characteristics: Killing-out proportion and composition. Meat Science, 72, 288-293.

Roque, A. P.; Osório, J. C. S.; Jardim, P. O.; Oliveira, N. M. \& Osório, M. T. 1999. Produção de carne em ovinos de cinco genótipos. 6. Desenvolvimento relativo. Ciência Rural, 29, 549-553.

Rosa, G. T.; Pires, C. C.; Silva, J. H. S. \& Motta, O. S. 2005. Crescimento alométrico de osso, músculo e gordura em cortes da carcaça de cordeiros Texel segundo os métodos de alimentação e peso de abate. Ciencia Rural, 35, 870-876.

Santos, A. C. P.; Ferreira, Â. C. D.; Bomfim, L. E. d. L. M.; Santos, L. F. \& Bispo, W. A. L. 2013. Cortes de carcaça de cordeiros alimetados com níveis crescentes de energia metabolizável. Synergismus scyentifica UTFPR, 8.

Santos, C. \& Pérez, J. 2000. Cortes comerciais de cordeiros Santa Inês. Encontro Mineiro de Ovinocultura, 1, 149-168.

Santos, J. R. S. d.; Pereira Filho, J. M.; Silva, A. M. d. A.; Cezar, M. F.; Borburema, J. B. \& Silva, J. O. R. 2009. Composição tecidual e química dos cortes comerciais da carcaça de cordeiros Santa Inês terminados em pastagem nativa com suplementação. Revista Brasileira de Zootecnia, 38, 2499-2505.

Sañudo, C. \& Sierra, A. I. 1986. Calidad de la canal en la especie ovina. Ovino. One.

Silva Sobrinho, A. 2001. Aspectos quantitativos e qualitativos da produção de carne ovina. Reunião Anual da Sociedade Brasileira de Zootecnia, 38, 425-446.

Silva Sobrinho, A. \& Silva, A. 2000. Produção de carne ovina. Revista Nacional da Carne, 24, 32-44.

Siqueira, E. R.; Natel, A. S.; Carvalho, S. R. S. T.; Oliveira, A. A. \& Fernandes, S. 2010. Composição tecidual do lombo e cortes das carcaças de cordeiros inteiros e castrados, submetidos a dois fotoperíodos. Revista Brasileira de Saúde e Produção Animal, 11, 25-32.

Sobrero, T. 1986. Aspectos poco difundidos de la cría lanar y vacuna. Hemisferio sur.

Tulloh, N.; Brimblecombe, H. \& Dennis, C. 1986. The effect of severe nutritional deprivation in early post-natal life on tissue and cellular responses during subsequent growth of lambs to the age of 4 months. The Journal of Agricultural Science, 106, 341350 .

Vargas Junior, F.M.; Leão, A.G.; Longo, M.L.; Osório, J.C.S.; Osório, M.T.M.; Leonardo, A.P. A situação dos pequenos ruminantes na América Latina: mercado e potencial futuro.In: Palestras do VIII Congreso Latinoamericano de Especialistas en Pequeños Rumiantes y Camélidos Sudamericanos, Campo Grande, Anais...ALEPRycs, p.79-87, 2013.

Vergara, H. \& Gallego, L. 2000. Effect of electrical stunning on meat quality of lamb. Meat Science, 56, 345-349.

Vergara, H.; Linares, M. B.; Berruga, M. I. \& Gallego, L. 2005. Meat quality in suckling lambs: effect of pre-slaughter handling. Meat Science, 69, 473-478.

Yamamoto, S. M.; Silva Sobrinho, A. G.; Pinheiro, R. S. B.; Leão, A. G. \& Castro, D. P. V. 2013. Inclusão de grãos de girassol na 
ração de cordeiros sobre as características quantitativas da carcaça e qualitativas da carne. Semina: Ciências Agrárias, 34, 19251934.

Zanette, P. M. \& Neumann, M. 2012. Confinamento como ferramenta para incremento na produção e na qualidade da carne de ovinos Containment as "tool" to increase in the production and quality of the meat of sheep. Ambiência, 8, 415-426.
Recebido em Junho 03, 2014.

Aceito em Agosto 12, 2014.

License information: This is an open-access article distributed under the terms of the Creative Commons Attribution License, which permits unrestricted use, distribution, and reproduction in any medium, provided the original work is properly cited. 